\title{
Flexible PVDF thin film as piezoelectric energy harvester
}

\author{
Norfaizul Izwan Nordin, Rosminazuin Ab Rahim, Aliza Aini Md Ralib \\ Department of Electrical and Computer Engineering, Kulliyyah of Engineering, International Islamic University \\ Malaysia, Malaysia
}

\begin{tabular}{l}
\hline \hline Article Info \\
\hline Article history: \\
Received Dec 28, 2018 \\
Revised Feb 20, 2019 \\
Accepted Mar 15, 2019 \\
\hline
\end{tabular}

Keywords:

Energy harvester

Piezoelectric

PVDF

\begin{abstract}
This aim of this paper is to study the potential of Polyvinylidene Fluoride (PVDF) polymeric piezoelectric film as an energy harvester for daily application use. PVDF offers several advantages over other piezoelectric materials such as high chemical strength and stability, high piezoelectric properties and biocompatible. Several investigations were carried out in this project which comprises of simulation, functionality test and application test. For functionality test, the highest voltage produced for a single film PVDF is $0.368 \mathrm{~V}$ which charges up a capacitor to $0.219 \mathrm{~V}$ in one minute. The highest voltage produced by multiple PVDF films is $1.238 \mathrm{~V}$ by stacking 10 films of PVDF in parallel which charges up to $0.688 \mathrm{~V}$ in one minute. For application test, 5 pieces of PVDF films were attached to a glove to generate some voltage during fingers bending activity. The highest output voltage recorded is $0.184 \mathrm{~V}$ which stores $0.101 \mathrm{~V}$ in a capacitor after 200 times of hand bending and releasing. As a conclusion, PVDF has a good potential as an alternative energy for daily application use. Combination of PVDF energy harvester system with proper power optimization circuit will open up rooms of research opportunities in energy harvester system with promising prospect in self-powered wireless electronics devices for Internet of Things application.
\end{abstract}

Copyright $\odot 2019$ Institute of Advanced Engineering and Science. All rights reserved.

\section{Corresponding Author:}

Rosminazuin Ab Rahim,

Department of Electrical and Computer Engineering,

Kulliyyah of Engineering, International Islamic University Malaysia, Malaysia.

Email: rosmi@iium.edu.my

\section{INTRODUCTION}

The process of capturing and storing a small amount of energy from heat, light, sound, vibration or movement is called energy harvesting. The generated energy can be used to power up low-energy electronic devices. There are many types of energy harvesting materials or devices that have been used and investigated such as thermoelectric material, pyroelectrics material, photovoltaic, electrostatic, the ambient radiation source, and piezoelectric materials. Different types of energy harvesting materials use different approach and principle to scavenge the energy.

Piezoelectric materials have the ability to convert mechanical stress or vibration to usable electrical power through piezoelectric effect. There are two types of piezoelectric effects which are direct and inverse in which the direct piezoelectric effect is used for energy harvesting purpose.

Numerous efforts of research and investigation have been reported on piezoelectric energy harvesting [1-13]. Piezoelectric materials that are commonly used include Polyvinylidene Fluoride (PVDF) $[14,15]$, Lead Zirconate Titanate (PZT) [16, 17] and Zinc Oxide (ZnO) [18, 19]. A piezoelectric thin film as a power generator for wearable device application has been developed by using poly(vinylidene fluoride-trifluroethylene) thin film [1]. It is able to produce $0.4 \mathrm{~V}$ of the maximum open-circuit voltage at approximately $0.25 \mathrm{~Hz}$ frequency of human hand. Another related work of energy harvesting in the wearable device was also demonstrated in [2]. PVDF and PZT were chosen to generate sufficient power to transmit a 
short-range identification code during walking by placing the RFID tag in a shoe. With $0.9 \mathrm{~Hz}$. frequency of walking pace, the power generates from PVDF stave and PZT dimorph is $1.3 \mathrm{~mW}$ and $8.4 \mathrm{~mW}$, respectively. Previous work also reported a prototype of a windmill that can generate electricity [3]. With controlled frequency of $6 \mathrm{~Hz}$ of rotation, the prototype generates $10.2 \mathrm{~mW}$ of power while $7.5 \mathrm{~mW}$ of power was generated when the fan is exposed to $10 \mathrm{mph}$ of wind. It was also reported that PVDF nanofibers that was directly written on the flexible substrates shows higher efficiency compared to PVDF thin films [4]. An optimization of PVDF based cantilever is proposed and validated with finite element circuit simulation [5]. Hence, the aim of this paper is to investigate the potential of PVDF material as a piezoelectric energy harvester. Several tests were conducted in this project which is simulation, release and bending test, functionality test and application test.

\section{PVDF FILM AS PIEZOELECTRIC ENERGY HARVESTER}

Piezoelectric materials have the ability to convert mechanical stress or vibration to usable electrical power. For energy harvesting, the direct piezoelectric effect is used. Polyvinylidene fluoride (PVDF) has been chosen as a piezoelectric material due to its chemical strength, flexibility, and stability compare to other materials. PVDF thin film has the lowest density of $1.78 \times 10^{3} \mathrm{~kg} / \mathrm{m}^{3}$ compare to $\mathrm{PZT}$ and $\mathrm{BaTiO}_{3}$ with each $7.5 \times 10^{3} \mathrm{~kg} / \mathrm{m}^{3}$ and $5.7 \times 10^{3} \mathrm{~kg} / \mathrm{m}^{3}$, respectively. PVDF thin film also has the highest $\mathrm{g}_{31}$ constant with $216 \times 10^{-3} \mathrm{Vm} / \mathrm{N}$ compare to PZT with only $10 \times 10^{-3} \mathrm{Vm} / \mathrm{N}$ and $\mathrm{BaTiO}_{3}$ with $5 \times 10^{-3} \mathrm{Vm} / \mathrm{N}$. The $g_{i j}$ represents the voltage coefficient while current coefficient is presented by $d_{i j}$. The $g_{i j}$ value determines the voltage based on (1) where $\mathrm{n}$ is 1,2 and 3 (1=length direction, $2=$ width direction, and $3=$ thickness direction); $\mathrm{g}$ is piezoelectric coefficient for the axis of applied stress; $X_{n}$ is the stress applied; $t$ is the thickness of the film.

$$
V_{o=} g_{3 n} X_{n} t
$$

The $g_{31}$ is the piezoelectric stress constant which is given as shown in (2) where where $E$ is an electric field; $T$ is the stress; $V$ is voltage; and $t$ is the sample thickness of the film.

$$
\left|g_{31}\right|=\frac{E}{T}=\frac{V}{(t)(T)}
$$

Meanwhile, $d_{i j}$ coefficient determines the value of charge density developed by the PVDF film. The $d_{i j}$ is a charge coefficient that carries the value piezoelectric strain constant depends on type of piezoelectric material used. From (3), it is shown that the charge density, $D$ is directly proportional to the charge coefficient $d_{i j}$ where $n$ is 1,2 and 3 (1=length direction, 2=width direction, and $3=$ thickness direction); $\mathrm{D}$ is the charge density develop; $\mathrm{Q}$ is charge develop, and $\mathrm{X}$ is stress applied.

$$
D=Q / A=d_{3 n} X_{n}
$$

\section{RESEARCH METHODOLOGIES}

The research work consists of few stages including COMSOL simulation to predict the behavior of PVDF thin film, functionality test to study the energy conversion mechanism and application test to validate the performance of PVDF thin film as potential energy harvester.

\subsection{Simulation}

The purpose of the simulation is to predict the behaviour of the PVDF thin films as energy harvester. The measured value from the simulation will be used as a reference for further experimental works. COMSOL Multiphysics is used to simulate the PVDF thin film in 3-D model environment.

\subsection{Functionality test}

Functionality test comprises of three parts which are release and bending test, single film test and multiple films test. The material used for this test is a PVDF thin film manufactured by Pro-Wave Electronics Corp. The dimension of the film is $25 \mathrm{~mm}$ x $13 \mathrm{~mm}$ of length and width, respectively.

\subsubsection{Release and bending test}

The release and bending test are conducted to measure the voltage generated from PVDF film as shown in Figure 1. The PVDF thin film is then connected to a basic rectifier circuit where 4 diodes are used to convert AC voltage produced from the PVDF film to DC voltage. A capacitor with a value of $100 \mu \mathrm{F}$ is used to store the generated voltage to be measure against time which is 1 minute. 


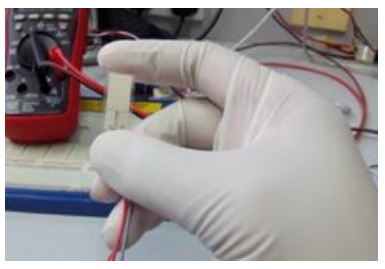

(a)

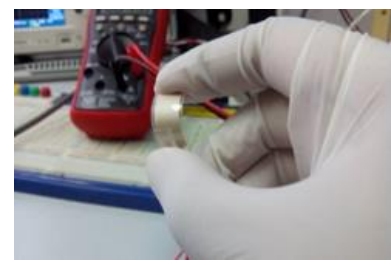

(b)

Figure 1. (a) The PVDF film in release state, (b) The PVDF film in bending state

\subsubsection{Single film with constant force test}

For single film application, output voltage produced from a single PVDF film is supplied to a rectifier circuit in which the voltage is stored in a capacitor for one minute. A multimeter and oscilloscope probes are attached in between the capacitor to measure the output produced from the film. It is worth noted that a DC servo motor is used in this test as a constant input to act as a force given to the PVDF film.

\subsubsection{Multiple film with constant force test}

For this section, the same test as previously described is conducted except now multiple films are being used. In multiple films test, the films are stacked in parallel and the number of films is increased from two to 10 films. The setup of the test is shown in Figure 2(a) while the arrangement of the PVDF films is shown Figure 2(b).

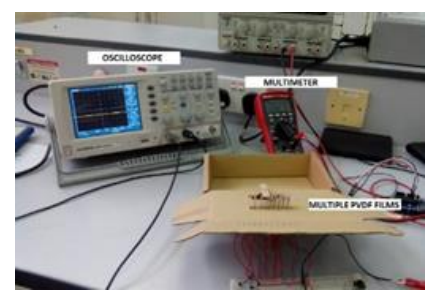

(a)

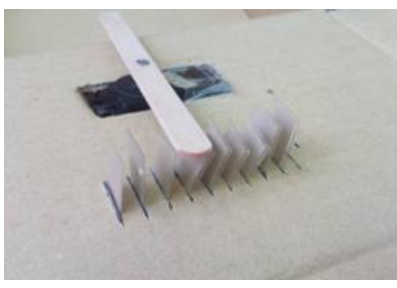

(b)

Figure 2. (a) Experimental setup, (b) The arrangement of PVDF film with DC servo motor as an input

\subsection{Application test}

In this application test, 5 pieces of PVDF films are used and connected in parallel. The test conducted is similar to the tests described in section B except the DC servo motor is now replaced by the movement of the hand. It should be noted that the movement of human's hand when bending is about $1.5 \mathrm{~Hz}$. The setup of the test is shown in the following Figure 3.

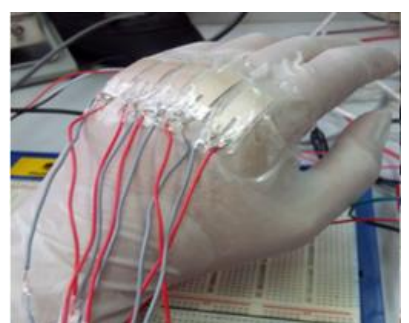

(a)

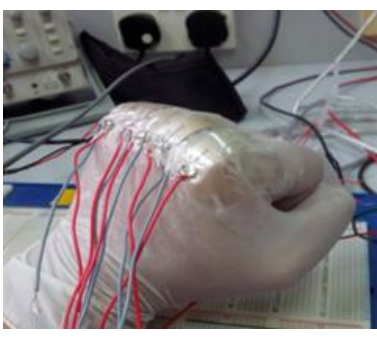

(b)

Figure 3. (a) Release movement of hand, (b) Bending movement of hand 


\section{RESULTS AND ANALYSIS}

In this section, results are obtained based on the tests described in Section 3.

\subsection{Simulation}

Simulation work comprises of two analysis which are eigenfrequency analysis and electric potential analysis. It was found out that for a given load of $1 \mathrm{~N} / \mathrm{m}^{2}$, the resonant frequency of the PVDF thin film is $0.02607 \mathrm{kHz}$ with electric potential generated at about $2 \mathrm{~V}$ along the $\mathrm{x}$-axis of the film as depicted in Figure 4.

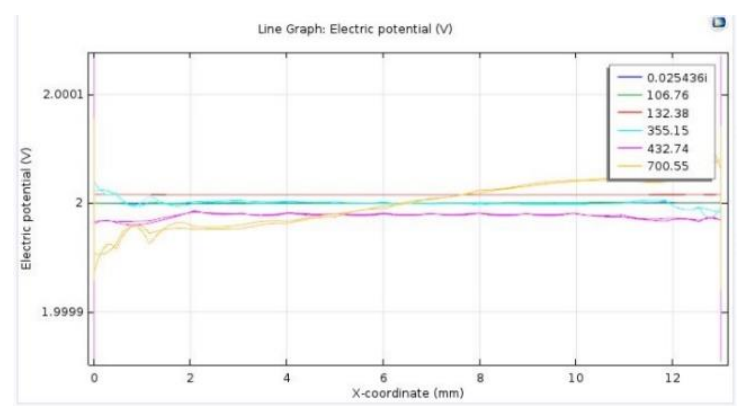

Figure 4. Electric potential of $2 \mathrm{~V}$ generated on PVDF thin film at $1 \mathrm{~N} / \mathrm{m}^{2}$ applied load

\subsection{Functionality test}

Results of functionality test are divided in three parts as below.

\subsubsection{Release and bending test}

The purpose of this test is solely to test the maximum voltage that can be produced by the PVDF film with a maximum force exerted by releasing and bending using hand. The maximum open circuit voltage recorded after converted to DC is around $0.24 \mathrm{~V}$. In one minute, the PVDF film managed to produce and store the voltage in a capacitor up to $0.055 \mathrm{~V}$. The result is presented in Figure 5.

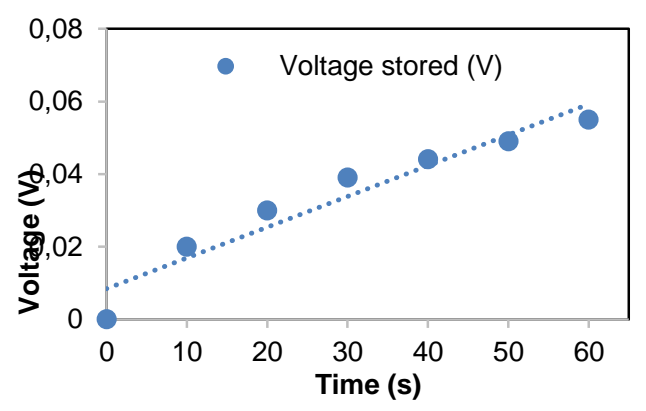

Figure 5. Graph of voltage stored in the capacitor versus time

\subsubsection{Single film with constant force test}

For constant force test, DC servo motor has been used to give a constant input of $80 \mathrm{rpm}$. The output voltage generated by a single film of PVDF based on average value is $0.368 \mathrm{~V}$. It is also shown that a single film of PVDF can store only around $219 \mathrm{mV}$ for 1 minute as shown in Figure 6. By this rate, it will take about 15 minutes to charge a capacitor to $3 \mathrm{~V}$ to apply it for only blinking an LED for example. 


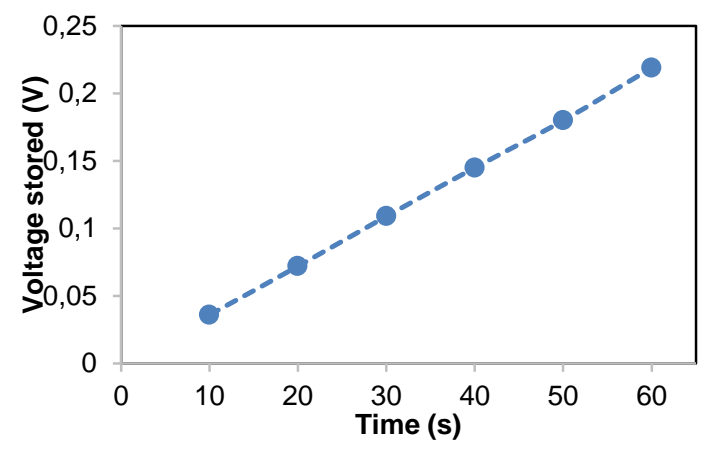

Figure 6. Graph of voltage stored against time with constant force

\subsubsection{Multiple film with constant force test}

Hypothetically, the more the number of films used, the higher the voltage will be generated in a period of time. For this experiment, all parameters from previous tests are kept constant except for the numbers of PVDF films used. The numbers of films used in this experiment is 2, 4, 6, 8 and 10 films which were connected in parallel. The lowest voltage produce in one rotation is $0.293 \mathrm{~V}$ for 2 pieces of films and the highest voltage was $1.115 \mathrm{~V}$ by using 10 films. Meanwhile, the voltage stored in a capacitor for 2, 4, 6, 8, and 10 films are $0.223 \mathrm{~V}, 0.320 \mathrm{~V}, 0.516 \mathrm{~V}, 0.617 \mathrm{~V}$ and $0.688 \mathrm{~V}$ respectively which are shown in Figure 7. From the graph, it is shown that the voltage stored in a capacitor is directly proportional to the number of films that has been used.

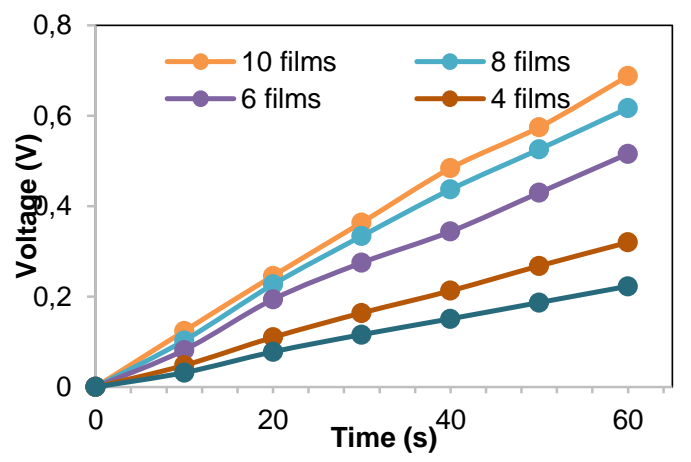

Figure 7. Graph of voltage stored vs time for various numbers of films

\subsection{Application test}

There are two steps involve in this test where the first step is to measure the maximum voltage generated by 5 films when it was attached to the glove and the other one is to store a voltage into the capacitor for 200 times of bending a hand with periodic frequency of $1.5 \mathrm{~Hz}$. For the first step, the maximum voltage recorded for the device is $0.184 \mathrm{~V}$. Meanwhile, for the second step, the voltage stored in a capacitor is $0.101 \mathrm{~V}$ after 200 times periodically of bending a hand with $1.5 \mathrm{~Hz}$ as shown in Figure 8. The main goal of this test is to try to implement the piezoelectric material as an energy harvester device in practical application in daily life. By considering the human activity or movement can virtually generate some force and energy, the piezoelectric material is used to harvest this energy and convert it to a useful energy. 


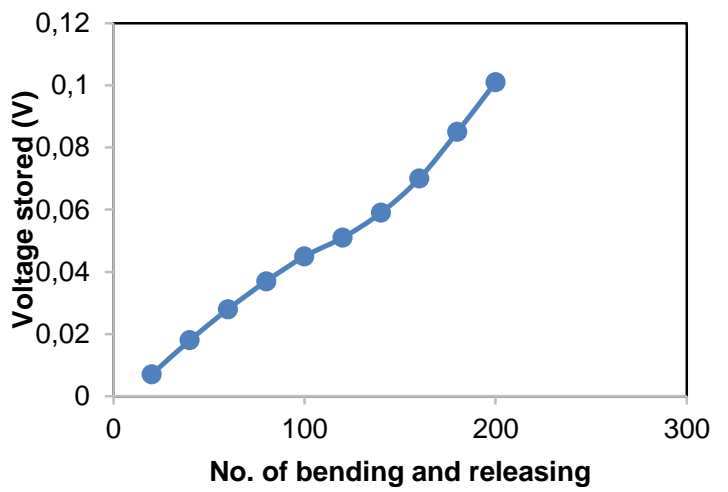

Figure 8 . Graph of voltage stored in a capacitor vs number of bending and releasing

\section{CONCLUSION}

As a conclusion, PVDF thin film can be used as potential energy harvester device for low power devices such as hearing aid, RFID tag and many MEMS devices which can be extended for Internet-ofThings application. The investigation of PVDF thin film resulted promising outcomes. For functionality test, the highest voltage produced for a single film of PVDF is $0.368 \mathrm{~V}$ which charges up $100 \mu \mathrm{F}$ capacitor to $0.219 \mathrm{~V}$ in one minute. The highest voltage produced for multiple films is $1.238 \mathrm{~V}$ by stacking 10 films of PVDF in parallel and it charges up to $0.688 \mathrm{~V}$ in one minute.

This area of interest has huge potentials to be discovered. The prospect of piezoelectric itself can benefit many parties as it is a unique material that can produce voltage from only mechanical forces. In this study, the only piezoelectric material that has been used is PVDF. There are many other materials that exhibit piezoelectric effect such as PZT and ZnO. For future studies, all of these materials can be compared in determining how much output voltage and power that can be produced. Other than that, there is a lot of rooms of improvement in terms of design of the energy harvester device itself as well as integration of power optimization circuit to ensure maximum output power can be generated.

\section{ACKNOWLEDGEMENTS}

This research was supported by Research Initiative Grant Scheme RIGS16-083-0247 from International Islamic University Malaysia and Ministry of Higher Education Malaysia.

\section{REFERENCES}

[1] S. S. Won et al., "Piezoelectric poly(vinylidene fluoride trifluoroethylene) thin film-based power generators using paper substrates for wearable device applications", Appl. Phys. Lett., vol. 107, no. 20, 2015.

[2] N. S. Shenck and J. A. Paradiso, "Energy scavenging with shoe-mounted piezoelectrics," in IEEE Micro, vol. 21, no. 3, pp. 30-42, May/Jun 2001.

[3] S. Priya, "Modeling of electric energy harvesting using piezoelectric windmill", Appl. Phys. Lett., vol. 87, 2005.

[4] Chieh Chang, Van H. Tran, Junbo Wang, Yiin-Kuen Fuh, and Liwei Lin "Direct-Write Piezoelectric Polymeric Nanogenerator with High Energy Conversion Efficiency", Nano Letters. 201010 (2), 726-731

[5] Jundong Song, Guanxing Zhao, Bo Li, Jin Wang, "Design optimization of PVDF-based piezoelectric energy harvesters", Heliyon 2017(3).

[6] A. A. M. Ralib, A. N. Nordin, and H. Salleh, "A comparative study on MEMS piezoelectric microgenerators," Microsyst. Technol., vol. 16, no. 10, pp. 1673-1681, 2010.

[7] I. Dakua and N. Afzulpurkar, "Piezoelectric Energy Generation and Harvesting at the Nano-Scale: Materials and Devices," Nanomater. Nanotechnol., vol. 3, pp. 1-16, 2013.

[8] J. C. Park, J. Y. Park, and Y. P. Lee, "Modeling and characterization of piezoelectric d33-Mode MEMS energy harvester," J. Microelectromechanical Syst., vol. 19, no. 5, pp. 1215-1222, 2010.

[9] A. A. M. Ralib, A. Nurashikin, and H. Salleh, "Fabrication techniques and performance of piezoelectric energy harvesters," 2009 3rd Int. Conf. Energy Environ., no. December, pp. 462-468, 2009.

[10] R. Elfrink et al., "Vibration energy harvesting with aluminum nitride-based piezoelectric devices," $J$. Micromechanics Microengineering, vol. 19, no. 9, p. 94005, 2009.

[11] Y. Luo, R. Gan, S. Wan, R. Xu, and H. Zhou, "Design and analysis of a MEMS-based bifurcate-shape piezoelectric energy harvester," AIP Adv., vol. 6, no. 4, 2016. 
[12] U. M. Jamain, N. H. Ibrahim and R. A. Rahim, "Performance analysis of zinc oxide piezoelectric MEMS energy harvester," 2014 IEEE International Conference on Semiconductor Electronics (ICSE2014), Kuala Lumpur, 2014, pp. 263-266.

[13] R. A. Rahim and M. J. B. Johari, "Design and Simulation of MEMS Helmholtz Resonator for Acoustic Energy Harvester," 2016 International Conference on Computer and Communication Engineering (ICCCE), Kuala Lumpur, 2016, pp. 505-510.

[14] Song, Jundong, et al. "Design optimization of PVDF-based piezoelectric energy harvesters." Heliyon 3.9 (2017): e00377.

[15] Karan, Sumanta Kumar, Dipankar Mandal, and Bhanu Bhusan Khatua. "Self-powered flexible Fe-doped RGO/PVDF nanocomposite: an excellent material for a piezoelectric energy harvester." Nanoscale 7.24 (2015): 10655-10666.

[16] Morimoto, Keiji, et al. "High-efficiency piezoelectric energy harvesters of c-axis-oriented epitaxial PZT films transferred onto stainless steel cantilevers." Sensors and Actuators A: Physical 163.1 (2010): 428-432.

[17] Xu, Ruichao, et al. "Screen printed PZT/PZT thick film bimorph MEMS cantilever device for vibration energy harvesting." Sensors and Actuators A: Physical 188 (2012): 383-388.

[18] Ralib, Aliza Aini Md, et al. "Fabrication of aluminium doped zinc oxide piezoelectric thin film on a silicon substrate for piezoelectric MEMS energy harvesters." Microsystem technologies 18.11 (2012): 1761-1769.

[19] Zhu, Guang, et al. "Flexible high-output nanogenerator based on lateral ZnO nanowire array." Nano letters 10.8 (2010): 3151-3155.

\section{BIOGRAPHIES OF AUTHORS}
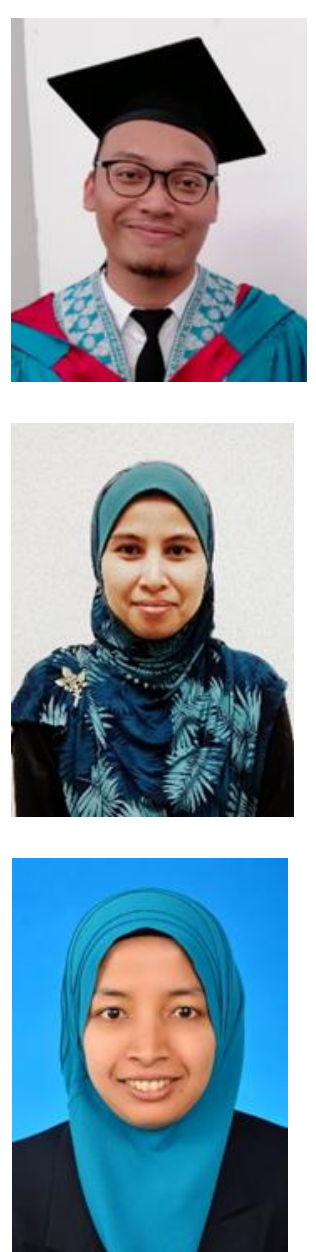

Norfaizul Izwan Nordin is a graduate from Kulliyyah of Engineering, International Islamic University Malaysia in B.Eng (Honours) Electronics-Computer Information Engineering. His research interests are energy harvester, communication network and programming.
Rosminazuin Ab Rahim currently works as an Assistant Professor at Faculty of Engineering, International Islamic University Malaysai after finishing her PhD in Engineering (MEMS \& Nanoelectronics) from Institute of Microengineering and Nanoelectronics (IMEN), Universiti Kebangsaan Malaysia in 2012. Back in 1999, she was a former graduate from Universiti Sains Malaysia in Electrical \& Electronic Engineering (Microelectronics) before continuing her studies at Universiti Kebangsaan Malaysia in MSc. Microelectronics in 2004. She obtained an industrial exposure from Delphi Packard Electric (M) Sdn Bhd from 1999 to 2001 where she worked as a Quality Engineer. Her research areas are related to MEMS device and fabrication where she was exposed to cleanroom-associated fabrication process while working on her $\mathrm{PhD}$ research on development of MEMS cantilever-based sensor. Her other research areas include piezoelectric energy harvester and biosensor.

Aliza Aini Md Ralib was born in Johor, Malaysia in 1982. She obtained her B. Eng. in Computer and Information Engineering (Electronics) from International Islamic University Malaysia in 2006. Both her MSc and PhD in Electronics Engineering are also from IIUM in 2011 and 2016 respectively. From 2009 to 2016, she was a Research Assistant at Universiti Tenaga Nasional Malaysia and IIUM. Since 2016, she has been Assistant Professor with the Electrical and Computer Engineering Department, International Islamic University Malaysia. Her research interests include Micro Electro-mechanical (MEMS), CMOS-MEMS acoustic wave resonators, electroacoustic sensors, piezoelectric thin film and MEMS piezoelectric energy harvesting. Upon completion of her $\mathrm{PhD}$, she decided to work on developing on surface acoustic wave sensors for breath analysis as noninvasive solution for early detection of critical disease. Her work has been published both locally and internationally in more than 34 papers in journals and proceedings locally and internationally. She has been awarded IEEE Postgraduate Award of Excellence in Outstanding Project in MEMS and Nanoelectronics organized by IEEE Electron Devices Society Malaysia Chapter in 2016. 